DOI: $10.17805 /$ trudy.2018.2.2

\title{
НОВЫЙ ГУМАНИЗМ (НЕОГУМАНИЗМ) КАК ИДЕОЛОГИЧЕСКАЯ ПАРАДИГМА ХХІ ВЕКА
}

\author{
Г. Г. Водолазов \\ Московский государственный лингвистический университет
}

Аннотация: Текст доклада автора на Всероссийской научной конференции «Культура между Логосом и Мифом: к проблеме бессознательного (к 80-летию А. Э. Воскобойникова)», которая прошла в Московском гуманитарном университете 26-27 октября 2017 года.

Ключевые слова: гуманизм; человечество; неогуманизм

\section{NEW HUMANISM (NEOHUMANISM) AS AN IDEOLOGICAL PARADIGM OF THE $21^{\text {ST }}$ CENTURY}

\author{
G. G. Vodolazov
}

Moscow State Linguistic University

\begin{abstract}
The text of the author's speech at the All-Russian Scientific Conference "Culture between Logos and Myth: On the Issue of the Unconscious (dedicated to the 80th anniversary of A. E. Voskoboynikov)", which was held at Moscow University for the Humanities on 26-27 October 2017.
\end{abstract}

Keywords: humanism; mankind; neohumanism

Сегодня, в XXI веке, человечество находится у черты перехода: от прежних форм социальной жизни к ее новым формам, от прежних форм мышления и идеологических парадигм к новым. Сегодня человечество у черты перехода:

1. от истории локального развития стран и цивилизаций к их сложно-противоречивому взаимодействию в рамках глобализации; у черты превращения мировой истории из суммы историй отдельных стран к подлинно всемирной истории; когда во многом по-новому ставится проблема о соотношении национальных государственных суверенитетов и глобальных общечеловеческих императивов; 
Научные труды Московского гуманитарного университета 2018 № 2

2. от ситуации миро-человеческого бессмертия к ситуации, когда человечество (после создания ядерного оружия) стало смертным (т. е. способным уничтожить самое себя);

3. от исчерпавшего свой потенциал развития классического капитализма (на Западе) к некоему новому обществу, сущность которого и название которого пока довольно туманно именуют «информационным» или «постиндустриальным» обществом;

4. от общественной системы, именовавшейся в СССР «реальным социализмом» (с подлинным социализмом не имевшей, впрочем, ничего общего и бывшей на деле государственно-бюрократической формацией, трансформировавшейся затем в некую разновидность олигархического капитализма»), к новому типу общественных отношений, в возможной (и желательной) перспективе - к Новому, гуманному, демократическому обществу, Обществу «реального гуманизма».

5. от ограниченного «узкосоциального» мышления к «ноосферному» мышлению;

6. от антагонизма либеральной и социалистической идеологий к их сближению и конвергенции;

7. от понимания прогресса как «развития материальных, производительных сил» человечества к пониманию прогресса как процесса снятия «отчуждения», как процесса «очеловечивания» мира и человека, как процесса освоения («присвоения») каждым индивидом всего богатства человеческой сущности.

Речь, по сути, идет о рождении принципиально нового Субъекта мировой истории и о возникновении Нового Мира, в котором этому Субъекту предстоит действовать. Действовать, естественно, по-новому, формулируя Новые Цели и Новые Идеалы, определяя Новые Средства их достижения. И в силу этого на место прежних мировоззренческих установок должно прийти Новое Мировоззрение, основной императив которого можно сформулировать так: «Очеловечивание Человека и Среды его обитания». «Очеловечивание» - что, в переводе на латинизированную терминологию современной мировой социально-политической теории, означает не что иное, как «Гуманизация». И, стало быть, Мировоззрение, провозглашающее в качестве главной задачи «Очеловечивание» (читай — «Гуманизацию») должно быть по праву названо Гуманизмом. Добавим только - Новым Гуманизмом (дабы отличить его от гуманизма «старого», традиционного). А основанная на этом мировоззрении стратегия преобразовательных действий, формулирующая цели деятельности современного Человека (что составляет содержание такого явления, как Идеология), может быть названа Идеологией Реального Гуманизма. 
В понятии «реального (нового) гуманизма» фиксируется главная цель и главная ценность нового мирового и российского социума - ЧЕЛОВЕК. Речь идет, в первую очередь, не о росте материального богатства общества, и даже не о развитии его производительных сил (хотя и то, и другое, безусловно, важно), а об ОЧЕЛОВЕЧИВАНИИ (ГУМАНИЗАЦИИ) деяТеЛЬНости Людей, о ликвидации отчуждения человека - от орудий его деятельности, от процесса и целей труда, речь идет о превращении каждого человека (в органическом единстве с другими) в подлинного и всемогущего субъекта истории, о превращении «хомо экономикус» (т. е. «экономического человека») в «человека творческого», в человека, перестающего быть придатком машины (при капитализме) или винтиком бюрократического механизма (при номенклатурных, псевдосоциалистических, режимах); речь идет о знаменитом - со времен Маркса - «скачке из царства необходимости в царство свободы», о превращении каждого индивида из односторонне сложившегося «профессионального кретина» (Маркс) в универсально и всесторонне развитого Человека.

Этим мировоззренческо-идеологическим принципам суждено поглотить и растворить в себе все великие идеологические концепции прошлого, и среди них, что особенно важно подчеркнуть, - идеологии, под знаком которых, в противоборстве которых прошли несколько последних столетий, - идеологии Либерализма и Социализма. Процесс этот пойдет, по-видимому, через сближение, сопряжение, взаимопроникновение, конвергенцию этих великих (в прошлом) идеологий и завершится их преодолением, их «снятием» (употребим этот, богатый содержанием, гегелевско-марксовский термин) в лоне Идеологии Нового (Реального) Гуманизма.

Да, «новая реальность», новизна мировой ситуации требует корректировки, а то и прямого пересмотра всех основных положений прежних социально-экономических, социально-политических теорий, идеологических и нравственных императивов. Надо только иметь в виду, что задача подобного пересмотра, задача выработки новых теоретических концепций стократно усложняется еще и тем, что мы еще не в Новой Реальности, а только на nepexоде к ней, что вступаем мы в Новую Реальность, отягощенные старыми противоречиями и конфликтами, повязанные прежними императивами, установками, формулами, прежними идеологическими парадигмами, традиционными формами мышления и действия. Поэтому столь драматичен этот процесс перехода к Новой Реальности и столь сложен мировой «контекст» всех сегодняшних проблем для его осмысления. 
Научные труды Московского гуманитарного университета 2018 № 2

\section{Основные принципы идеологии Нового гуманизма}

Идеология Нового типа, Идеология современного гуманизма, в отличие от идеологических построений социализма и либерализма, исходит из приоритета не классовых, а общечеловеческих, общемировых интересов и ценностей (что связано с превращением когда-то «бессмертного» субъекта мировой истории в «смертного», способного уничтожить самого себя). Таков первый, важнейший, принцип неогуманизма.

Почему нужны новые идеологические подходы? С чем связана опасность следования императивам прежних идеологий в современном мире?

Так, классическая социалистическая идеология (с её установкой на преодоление социального неравенства через революцию, начинающуюся на национальной почве и превращающуюся в мировой революционный процесс, с её принципами классовой борьбы и благодетельности революционного насилия, с её допущением возможности гражданской войны с миром капитала) может подвинуть мир на грань ядерной катастрофы с почти неизбежным уничтожением не просто мира капитала, но вообще Человеческого мира.

И классический либерализм, славивший стихию социального процесса и видевший роль великого регулятора социально-экономической деятельности в «невидимой руке рынка», в частной собственности, в свободной конкуренции, порождающей социальное неравенство (мощное, по уверению либералов) условие для развития инициативы каждого собственника, каждого человека, не в состоянии дать адекватного ответа на вызовы XXI века. Ценимая либерализмом мировая рыночная стихия рождает тяжелейшие всемирные экономические кризисы; а становящаяся всё более жёсткой и жестокой рыночная конкуренция создаваёт монополистических монстров, подминающих под себя более слабых предпринимателей; схватки этих монстров на мировой арене, как показывает опыт XX столетия, рождают национальные (а то и мировые) войны (что чрезвычайно опасно в наш ядерный век). Кроме того, прославляемое либерализмом (в качестве стимула экономической активности) социальное неравенство, распространяется не только на свою национальную публику, но и на целые страны, стимулируя восстания против народов «золотого миллиарда». Так что и либералам придется считаться со «смертностью» современного человечества: ограничивать свою рыночную стихию «видимой рукой» общественного (государственного) регулирования, программирования и существенно смягчать «неравенство» (на национальной и мировой аренах). А также - существенно ограничивать культ Индивидуальности, подчиняя её интересы общенациональным и мировым. 
Второй принцип идеологии Нового гуманизма связан с превращением Человечества из локально-разделенного в глобально-целостного. Его суть: исходить из приоритета глобальных интересов перед локальными, перед национально-государственными, при сохранении, однако, национальной идентичности. Отсюда рождается задача сил, доминирующих на мировой, глобальной арене: не подавить, не растворить в глобальном социуме локальные цивилизации, а создать условия для развития их локальной (национальной) специфики, для её сопряжения с логикой мирового развития. А задача сил национально-локальных образований может быть сформулирована по образцу, созданному (применительно к России) ещё Пушкиным: «Войти в Европу и остаться Россией». Что сегодня могло бы звучать так: «Войти в глобальный мир, сохраняя свою (преобразованную светом глобальности) национальную идентичность». «Войти в глобальный мир и остаться Россией, Ираном, Ираком, Сирией, Украиной...» На необходимость соединения «локального» с «глобальным» обратил внимание Генеральный секретарь ООН в «Докладе-миллениуме»: «Государства должны более глубоко осознать их двоякую роль в нашем глобальном мире. Помимо той ответственности, которую каждое государство самостоятельно несет перед своим обществом, на государствах лежит коллективная ответственность за нашу общую жизнь на этой планете - жизнь, общую для граждан всех стран. Успешное управление процессом глобализации, таким образом, требует - прежде всего, - чтобы государства действовали в соответствии с их двоякой ролью». «Двоякость роли» современных государств - важная черта современного гуманизма.

третий принцип. Здесь речь идёт об отношении Новой идеологии к своим идеологическим предшественникам - концепциям либерального и социалистического толка: они не отбрасываются, не перечеркиваются, а в существенно преобразованном виде включаются в корпус идей Новой идеологии - поскольку в прежних идеологиях сохраняется некое живое содержание, целый ряд интенций, сыгравших серьёзную позитивную роль в истории человечества и могущих, в существенно преобразованном виде, еще сыграть. Главное «преобразование» прежних идеологий - либерализма и социализма - связано с процессом их сближения, сопряжения, с их, в итоге, объединением в некоем новом идеологическом построении, органически сочетающем в себе либеральные и социалистические ценности и императивы. В рамках идеологической парадигмы Нового гуманизма существенно изменяется само взаимоотношение либеральной и социалистической идеологий - процесс идёт от их прежнего фронтального противостояния к их сопряжению, к их «конвергенции». На этом стоит остановиться поподробнее, ибо конвергенция демократически-гуманистических ценно- 
Научные труды Московского гуманитарного университета 2018 № 2

стей либерального и социалистического типа ведёт к формированию современной социальной теории, которая способна указать выход из тупиков современного мирового и российского бытия.

Конвергенция прежних идеологий. Итак, общая логика всемирной истории: возникновение, развитие (через противоречия) и снятие Отчуждения. Это, повторяю, общая логика. Ее непросто было выявить и описать. И заслуга в этом Гегеля, Маркса и их учеников из XX века - Ильенкова, Лукача, Батищева, Межуева - велика.

Но, пожалуй, еще труднее описать, определить, понять конкретное состояние (содержание) отчуждения в конкретную историческую эпоху. Отчуждения, проявляющегося во всей системе общественных отношений - в сфере экономики, культуры, политики, общественного сознания. И на основе этого понимания дать императивы, лозунги деятельности силам «прогресса» и «гуманизма». В эпоху Современности эту задачу пытались решать различные идеологии, среди которых особенно значимое место (в особенности в XIX и XX веках) занимали соперничавшие между собой идеологии либерализма и социализма. Они стремились (каждая идеология по-своему) отражать Логику всемирной истории, в ее контексте - логику развития современных им общественных отношений, их современное состояние и перспективы их развития. Стремились определить главных субъектов социального развития и выработать для них программу действий.

История либерализма и социализма, их исторического противостояния - сюжет для «очень большого рассказа», для не одной монографии. Здесь хотелось бы обозначить главную нить их истории, главные черты их современного состояния.

Вообще сущность этих идеологий в наикратчайшем виде зафиксирована их выдающимися представителями - либералом Людвигом фон Мизесом и социалистом Карлом Марксом.

Людвиг фон Мизес: «Программа либерализма, если выразить ее одним словом, будет читаться так: собственность, т. е. частное владение средствами производства... Все остальные требования либерализма вытекают из этого фундаментального требования» («Либерализм в классической традиции»).

Карл Маркс: «...Коммунисты могут выразить свою теорию одним положением: уничтожение частной собственности» («Манифест коммунистической партии»).

Как видим, - идеологии-антиподы. Противостояние - фронтальное. Когда и как они возникли, какие этапы прошло это их противостояние, что ждать от этого противостояния в будущем?

Они и возникли как антиподы, по-разному оценивающие реальность - 
процесс становления капитализма. Правда, либеральные теории были более теоретически разработаны. Социалистические - отличались импрессивностью, мечтательностью. Либеральные теории описывали то, что есть - реальность, ее суть, противоречия, ее реальные тенденции. Либерализм был прагматичен и реалистичен. Социалистические теории, сталкиваясь с противоречиями реальности, строили планы, как от них возможно скорее избавиться, фантазировали насчет того, каким непротиворечивым, гармоничным и гуманным мог бы быть социальный мир. Социалистические авторы рисовали некие идеалы, в которых воплощались бы их мечтания о социальной гармонии, не задумываясь особенно над тем, есть ли социальные и культурные силы, способные и готовые эти их мечты осуществить. Им казалось: достаточно нарисовать красивую, увлекательную картинку будущего - и люди немедленно кинуться воплощать эту красоту в жизнь.

Классические либеральные теории (Джона Локка и Адама Смита, в первую очередь) описывали логику перехода от феодализма к капитализму. И базисным пунктом их теорий была защита свободно функционирующей частной собственности, освобожденной от феодальных пут. И главное устранить вмешательство государства и чиновничества в движение частной собственности, реализующей себя в рыночной экономике. «Невидимая рука рынка» (А. Смит) всё сама отрегулирует; во всяком случае - лучше, чем государственная бюрократия. В общем - laissez-fair, laissez-passer! Практика, основанная на идеях либерализма, была громадным шагом в развитии производительных сил общества, политического и культурного социального прогресса. Либеральные теоретики раскрыли громадную прогрессивную роль буржуазных отношений в истории человечества и тем внесли существенный вклад в социальную науку. Можно сказать, что ими зафиксирован сделанный человечеством шаг вперед в направлении смягчения «отчуждения» (хотя классики раннего либерализма этот термин не употребляли).

Но буржуазный строй не был формой «снятия отчуждения», а лишь его (отчуждения) новой формой. Да - расширяющей возможности прогресса производительных сил и, на базе этого, - приоткрывающей новые возможности и перспективы гуманизации социума. И всё же отчуждение, особенно в форме эксплуатации лишенного собственности трудящегося человека, сохранялось. И это состояние сохраняющегося «отчуждения» болезненно переживалось низшими классами. Работник оставался «частичным» человеком, эксплуатируемым, униженным существом. Что и фиксировали гуманно настроенные люди того времени (социалисты, в первую очередь). Им хотелось, чтобы прогресс не сопровождался такими тяжелыми чертами. Тогда-то они и принялись сочинять общество, где частная собственность заменялась бы общественной. Общество, где не «невидимая рука рынка» 
Научные труды Московского гуманитарного университета 2018 № 2

регулировала бы экономические отношения, а государство, и где рыночная экономика сменялась бы плановой. В общем - общество, как сказали бы сегодня, без отчуждения.

Ведь исходным было их лобовое противостояние: вспомним: императивы Томаса Мора и Джона Локка, в которых либерализм и социализм предстают, как абсолютные идеологические антиподы:

1. Частная собственность (Локка) против общественной собственности (Mopa);

2. Стихия свободного рынка (Локка) против плановой экономики (Mopa);

3. «Минимальное» государство (Локка) против государства «во всём» (Mopa);

4. «Свобода» (Локка) против «равенства» (Мора).

Как оценить эту фазу противостояния двух идеологий?

Не может быть никаких сомнений, что либеральные теории той поры несравненно содержательнее, несравненно реалистичнее и научнее социалистических. Они давали теоретическое обоснование, теоретическое оправдание процессу перехода человечества от феодальных отношений к капиталистическим. Они мощно стимулировали экономический (да и культурный) прогресс общества. Правда, они не уделяли слишком большого внимания тому, как чувствуют себя в условиях капитализма люди из низших социальных слоев: много ли им перепадает из этого бурного экономического прогресса. Ими подчеркивалось (и справедливо!), что даже эти низшие социальные слои получали определенные выгоды от смены феодального строя буржуазным: бесправный, крепостной работник феодального общества становился лично свободным, свободным (хотя и наемным) работником, получал определенные политические права и возможности культурного роста. Что же касается его зависимого экономического (а вследствие этого и политического) положения, то иначе, подразумевалось, просто нельзя. Ликвидировать частную собственность и осуществить «всеобщее равенство» - значило бы разрушить все стимулы общественного развития.

А вот их антиподы, социалисты, обращали свое внимание как раз на эти страдающие слои. Они взывали быть неравнодушными к судьбе людей из этих слоев. Они не давали обществу успокоиться, они будоражили его. И в этом была их громадная историческая заслуга. Да, экономически и политически их проекты и императивы были неосуществимы, а подчас и просто реакционны, ибо силились прервать восходящий (хотя и противоречивый) исторический процесс. Пытались перепрыгнуть исторически неизбежные этапы развития, подменив социальные законы субъективными мечтаниями. Да и просто произволом (хотя и выглядевшим вроде бы очень гумани- 
стичным). Да, прожекты ранних социалистов были утопичными, неосуществимыми. Но не бессмысленными и не бесплодными. Они развивали - пусть не экономическую, пусть не политическую - но морально-нравственную культуру общества. Будили его совесть. Хорошо сказал однажды Энгельс: «Ложное в формально-экономическом смысле может быть истиной в всемирно-историческом смысле».

Этой истиной во всемирно-историческом смысле и был ранний социализм - социализм Мора, Кампанеллы, Сен-Симона, Фурье, Оуэна. Они предсказывали возможность устранения эксплуатации (т. е. - снятия отчуждения). Они зажигали - пусть далекие - но маяки, на свет которых могли ориентироваться гуманистически настроенные люди. Они способствовали развитию, наращиванию Человеческого капитала, они создавали нравственное богатство общества, тот нравственный задел, который может сыграть большую роль на более поздних этапах человеческой истории.

Так что развитие идей «очеловечивания», идей гуманизма происходило в рамках обеих идеологий. Хотя и по-разному. Практика либерализма способствовала смягчению отчуждения путем наращивания материальных благ, производительной силы человека. Социалистическая теория стимулировала духовное, нравственное, культурное развитие общества. В общем, обе идеологии освещали и развивали разные стороны гуманистического процесса и гуманистической теории, в рамках которой и будет происходить процесс их сближения.

B XIX веке социалистические идеи всё больше утрачивают черты утопизма. Всё больше превращаются в реалистическую стратегию социальных преобразований. Ибо капиталистический социум, развивавшийся в контексте либеральных теорий, выходит на рубежи, когда «очеловечивание» (смягчение, а в перспективе - уничтожение эксплуатации) низших сословий и классов становится реальной возможностью (а то и просто необходимостью, с точки зрения успешного социального развития). Что и было зафиксировано марксистским социализмом.

Хотя противостояние либерализма и социализма продолжается, но меняется его формат. Если раньше это было противостояние реалистического либерализма и утопического социализма, то теперь - это противостояние двух реалистических концепций (хотя и по-разному реалистических).

А в XX веке происходит новый поворот в их историческом споре. Социальная практика XX столетия начинает рушить основополагающие принципы классической либеральной теории. Выясняется, что «невидимая рука рынка» больше не является удачным регулирующим фактором. «Свободный рынок», рыночная стихия порождает всё более глубокие, всё более масштабные кризисы - вначале экономические, а потом и общесоциальные. 
Научные труды Московского гуманитарного университета 2018 № 2

Наиболее трагическое проявление этого кризиса - Первая мировая война. Свободная рыночная конкуренция, сопровождавшаяся поначалу демократизацией общественной жизни, породила могучих монополистических хищников и их жестокую схватку на мировой арене, стоившую человечеству 10 миллионов жизней.

Первая мировая война и всеобщий, глобальный кризис 20-х годов ясно засвидетельствовали, что оптимизму и реализму классического либерализма (от Локка и Смита до Людвига фон Мизеса) пришел конец. Что громко и безапелляционно зафиксировал один из виднейших теоретиков либерализма Джон Кейнс в своей работе 1925 года «The End of Laissez-fair», то есть: Конец того старого прекрасного либерализма, императивы которого были когда-то сформулированы Локком и Смитом. И развернуто, масштабно - в работе «Общая теория занятости, процента и денег» (1936 г.) - о «регулируемой» государством и обществом рыночной экономике, которая у Кейнса перестает быть «свободно-рыночной», «стихийно-рыночной», постепенно превращаясь в экономику «планово-рыночную». «Новый либерализм» Кейнса начинает включать в себя целый ряд императивов и ценностей, присущих социалистической идеологии. «... посткейнсианство, - пишет профессор Солтан Дзарасов, - объективно оказывается ближе к марксизму и социализму, чем к либерализму и капитализму», а «вектор этого движения... задал сам Кейнс своим посягательством на неоклассические постулаты. Наиболее убедительное подтверждение верности этого утверждения мы находим в государстве благосостояния (Welfare State). Его идейными вдохновителями были Джон Кейнс, давший ему теоретическое обоснование и William Beveridge (1879-1963), разработавший прикладные аспекты перехода к такому государству в развитых странах. Оба были либералами, а предложенные ими идеи, по существу, социалистическими и осуществлены в Англии лейбористами, а в континентальной Европе - социал-демократическими партиями» (Дзарасов, 2012: 196).

И движение навстречу с другого полюса: 1921 год - введение НЭПа в послереволюционной России.

Ленин: «Мы вынуждены признать коренную перемену всей точки зрения нашей на социализм».

Что это значит? В чем состоит эта перемена?

- допущение разных форм собственности, сопряжение общественной и частной;

- сочетание рыночной стихии и плана;

- ограничение вмешательства государства в экономику;

- поддержка духовного (и политического) плюрализма;

- равенство, не разрушающее свободу. 
Возникают, иначе говоря, «Конвергентный либерализм» (Кейнса) и «Конвергентный социализм» (в духе нэповского социализма Ленина).

За какой из вышеназванных «конвергентных теорий» будущее? Это предмет дискуссий.

Один из возможных вариантов: Встреча на теоретической «Эльбе» конвергентного либерализма и конвергентного социализма. Произойдет, скорее всего, не слияние их в одну идеологию, а - дружеское соревнование (чередование во власти) - демократического конвергентного либерализма и демократического конвергентного социализма. Сложится биполярная идеологическая и социально-политическая система. И будет социальный корабль покачиваться между двух неантагонистических курсов. И такой, зигзагообразный, путь будет эффективней прямолинейно-одностороннего. И это будет важной составляющей пути к той идеологии (и основанной на ней социальной системе), которую можно назвать «Реальным Гуманизмом».

Четвёртый принцип. Приоритет морали перед политикой. Сопряжение Политики и Нравственности. Становление Нравственной, Гуманистической политики. В основе политики (как процесса согласования интересов) лежит, как известно, принцип насилия («легитимного насилия» - Макс Вебер), нравственность - ненасильственный способ согласования интересов. Насилие всегда порождает контрнасилие, оно чревато возникновением опасных конфликтов, которые, в своём развитии, могут подвести народы к черте ядерной катастрофы. Расширение пространства ненасильственных действий - вот важный лозунг современной эпохи. Да, в нынешнем мире сильно противостояние социальных и национальных интересов. И без определённых форм насилия, увы, не обойтись. Но насилие в политике сегодня утрачивает своё прежнее универсальное значение. Насилие, соединенное с ядерным оружием, становится смертельно опасным для человечества. Новая реальность требует Нравственной политики, императив которой: «максимальная минимизация насилия».

Новизна современной формы гуманизма состоит в том, что Человечество в своём развитии подошло к черте, когда уже можно ставить вопрос не просто о смягчении отчуждения (как то было в прежних гуманистических теориях), а о его снятии, о его ликвидации. «Ставить вопрос» - значит убеждать граждан в необходимости его решения, которое станет реально возможным, когда массовые силы гражданского общества в полной мере осознают эту необходимость.

Сегодня мы находимся на пороге нового «века Просвещения», в чём-то аналогичного французскому Просвещению XVIII столетия. Сегодня, в первую очередь, не структурные, не институциональные изменения важны, а преобразование общественного сознания. Можно сказать, речь идёт о «ре- 
Научные труды Московского гуманитарного университета 2018 № 2

волюции» в человеческих головах, которая затем, наверняка, перерастёт в масштабное переформатирование социально-экономической и политической действительности, в реализацию социального идеала Гуманизма.

\section{Императивы гуманистической политики}

1. Гуманистическая политика - это политика с человеческим лицом. Политический гуманизм - это не совокупность всем известных абстрактных «человеколюбивых» пожеланий. Это - стратегия социально-политической деятельности, которую можно (и нужно) назвать реальным гуманизмом. Это не фразы, это - деятельность, стратегия, направленная, в каждом своем шаге, на расширение пространства свободы человека, на расширение социального равенства людей, на их материальное благополучие, на их культурное развитие.

2. Гуманистическая политика - это политика, направленная на подключение каждого человека к участию в решении вопросов развития своей страны, своего общества. Это - то, что может быть названо «стратегией горизонтали».

В последнее время в ряде стран на постсоветском пространстве получила распространение так называемая «стратегия вертикали». Стратегия, нацеленная на преодоление анархии, социальных кризисов и нестабильности 1990-х годов, Стратегия социальной и политической стабилизации. И политическая вертикаль, действительно может обеспечить стабилизацию. Но...

Но обеспечить поступательное, нарастающее, ускоряющееся развитие стран и обществ «вертикаль» не в состоянии. Ибо Вертикаль - это стратегия модернизации и мобилизации управления государственных служащих, государственных чиновников. Она не ставит и не выполняет задачу подключения к социальной деятельности всего богатства народных, гражданских сил, всех талантов общества. Стратегия вертикали может иметь успех только в качестве временной стратегии. В долговременной же перспективе она ведет к нарастанию и разрастанию элементов авторитаризма, а то и тоталитаризма - то есть политических режимов, резко сокращающих участия граждан в управлении делами общества.

Стратегия же Горизонтали является стратегией, способствующей становлению и развитию институтов и структур гражданского общества. Это - стратегия мобилизаций усилий не только чиновничьего мира, но - всего общества (на всех уровнях).

Гуманизм этой стратегии раскрывается в полной мере в том, что люди перестают быть бессловесными и мало что значащими винтиками в социальной машине, управляемой бюрократией, перестают быть только исполнителями начальственной воли, они становятся деятелями и творцами. 
И тем самым реализуется то, что составляет важную составляющую человеческой сущности.

Следует только добавить, что стратегия горизонтали вовсе не должна противостоять стратегии вертикали. Она должна дополнять ее: Вертикаль способна обеспечить «диктатуру закона», а Горизонталь - участие граждан в выработке этих законов и в массовом контроле за их исполнением.

3. Гуманистическая политика - это политика сокращения рабочего времени и роста свободного времени, и на основе этого - расширения пространства Свободы для каждого индивидуума.

Свободное время делает человека не материально, а духовно богатым существом, позволяя ему включаться в процесс общественного производства в качестве совершенно «иного субъекта» деятельности. «Свободное время - представляющее собой как досуг, так и время для более возвышенной деятельности - разумеется, превращает того, кто им обладает, в иного субъекта, и в качестве этого иного субъекта он и вступает затем в непосредственный процесс производства» . Возвышение индивида до уровня такого субъекта и есть одна из целей современной гуманистической политики.

4. Политика только тогда имеет шанс стать гуманистической политикой, когда она налаживает равноправное сотрудничество с социальной Наукой, ибо назначение социального Научного Знания - выражать не интересы отдельных общественных групп, сословий и классов (что преобладает в политической деятельности), а интересы общественного развития в целом, или, говоря возвышенным гегелевским языком, - истину общественного развития.

5. Гуманистическая политика - это политика, обеспечивающая все основные свободы человека, политика идеологического плюрализма и самой широкой демократии.

6. Гуманистическая политика, это - политика нового, глобального, мышления, заменяющая классовые критерии общечеловеческими, политика, которая направлена на кооперацию, объединение Человечества при сохранении национальной идентичности и уважения к истории и культуры каждой страны, каждого народа. Гуманистическая политика на международной арене это - обеспечение единства разнообразного, это - многополюсный мир.

7. Гуманистическая политика, это - политика, заботящаяся, в первую очередь, не о «будущих поколениях», а о ныне живущих поколениях. И только свободно живущие и экономически процветающие нынешние поколения способны обеспечить благоприятную преемственность для поколений будущих. Ни одно поколение не может быть «навозом», удобряющим историческую почву для некоего «светлого будущего». 


\section{СПИСОК ЛИТЕРАТУРЫ}

Дзарасов, С. (2012) Куда Кейнс зовет Россию? М. : Алгоритм. 304 с.

Водолазов Григорий Григорьевич - доктор философских наук, профессор, главный редактор журнала «Мегаполис», профессор кафедры политической теории Московского государственного лингвистического университета. Адрес: 119021, Россия, Москва, ул. Остоженка, д. 38 стр. 1. Тел.: +7 (499) 246-19-82. Эл. адрес: gvodolazov@yandex.ru

Vodolazov Grigoryi Grigoryevich, Doctor of Philosophy, Professor, Editorin-chief of Megapolis journal, Professor, Department of Political theory, Moscow State Linguistic University. Postal address: 38, Bldg. 1, Ostozhenka Str., 119021, Moscow, Russia. Tel.: + 7 (499) 246-19-82. E-mail: gvodolazov@yandex.ru

\section{Для цитирования:}

Водолазов Г. Г. Новый гуманизм (неогуманизм) как идеологическая парадигма XXI века [Электронный ресурс] // Научные труды Московского гуманитарного университета. 2018. №2. URL: http://journals.mosgu.ru/trudy/ article/view/689 (дата обращения: дд.мм.гг.). DOI: 10.17805/trudy.2018.2.2 